\title{
A Blancanieves Andaluza de Pablo Berger: Tradução e Intermidialidade
}

\section{An Andalusian Blancanieves by Pablo Berger: Translation and Intermediality}

Roseli Barros Cunha* 
Resumo: Em 2012, Schneewittchen - ou Branca de Neve, como a conhecemos em português -, dos irmãos Jacob e Wilhelm Grimm (1812), ganha mais uma releitura. 0 filme Blancanieves, do diretor Pablo Berger, é inspirado no conto (mais especificamente, Märchen) recolhido da tradição oral pelos filólogos alemães. A proposta deste artigo é, partir de duas traduções para o português do Brasil, a saber, a de Tatiana Belinky (2013) e a de Christine Röhrig (2014), examinar as relações intermidiáticas entre as obras literária e cinematográfica à luz dos estudos de Irina Rajewsky (2012) e Claus Clüver (2011), principalmente, no que se refere à caracterização da personagem principal, Branca de Neve, de seus pais, do lugar e da época onde ocorre a ação tanto do conto quanto do filme. Na produção de Berger, personagens, espaço e tempo contidos na obra dos Grimm são evidentemente ressignificados a partir de elementos do flamenco e das touradas, associados à cultura tradicional cigana presente, por sua vez, na tradição popular do sul da Espanha. A presença desses elementos faz com que a obra dialogue com outras produções bastante conhecidas sobre tais temáticas e os estereótipos que se perpetuam em relação a elas tanto na Espanha quanto fora dela ao longo de séculos. Analiso como ocorre o processo de ressignificação e de que modo ela discute ou não conceitos e preconceitos sobre elementos populares e tradicionais muito associados ao que se costuma entender por 'cultura espanhola', principalmente a partir do apoio teórico de Rafael Jover (2007), Francisco Aix Gracia (2002) e Gerhard Steingresse (2002).

Palavras-chave: Estudos da Tradução; Intermedialidade; Cinema espanhol; Flamenco; Tradição oral.

Abstract: In 2012, Schneewittchen - or Snow White, as we know it in English-, by brothers Jacob and Wilhelm Grimm, gets another rereading. Director Pablo Berger's film Blancanieves is inspired by the tale (more specifically, Märchen) taken from the oral tradition by German philologists. Based on two translations into Brazilian Portuguese, namely Tatiana Belinky (2013) and Christine Röhrig (2014), I examine the intermediate relations between literary and cinematographic works in the light of Irina Rajewsky (2012) and Claus Clüver (2011), especially with regard to the characterization of the main character, Snow White, his parents, the place and time where the action of both the tale and the film takes place. In Berger's production, characters, space, and time contained in the Grimm's work are evidently resignified from elements of flamenco and bullfighting, associated with the traditional Gypsy culture present, in turn, in the popular tradition of southern Spain. The presence of these elements makes the work dialogue with other well-known productions on such themes and the stereotypes that perpetuate in relation to them both in Spain and abroad for centuries. I analyze how the process of resignification takes place and how it discusses or not concepts and prejudices about popular and traditional elements very associated with what is commonly understood by 'Spanish culture', especially from the theoretical support of Rafael Jover (2007), Francisco Aix Gracia (2002) and Gerhard Steingresse (2002).

Keywords: Translation Studies; Intermediality; Spanish cinema; Flamenco; Oral tradition.

TradTerm, São Paulo, v.38, fevereiro/2021, p. 234-251

Número Especial - III JOTA

www.revistas.usp.br/tradterm 


\section{Considerações iniciais sobre intermidialidade e flamenco}

Em 2012, Pablo Berger produziu o filme espanhol Blancanieves explicitamente inspirado no conto Branca de Neve, recolhido e recriado pelos irmãos Jacob e Wilhelm Grimm e publicado em 1812. A produção do diretor basco remete-nos aos antigos filmes do início do século XX: é mudo, com intertítulos em espanhol, e em preto e branco. Para este trabalho, as citações foram realizadas a partir da cópia em DVD distribuída pela Imovision, em 2013 no Brasil.

Entretanto, em Blancanieves de Berger também são perceptíveis alusões a elementos presentes em muitas outras produções, uma delas o romance Carmen do francês Prosper Mérimée, de 1845, e na ópera de mesmo nome de Georges Bizet, estreada em 1875. Além dessas, outras obras menos conhecidas do grande público podem ser recordadas a partir da produção de Berger, tal como o filme Carmen la de Triana, de Florián Rey, de 1938, rodado em Berlim (JOVER 2007: 15).

Interessante perceber que o filme de Berger está ambientado no início do século XX, período bastante aproximado ao da produção de Rey. Deste modo, é notável que, além de o filme ser uma transposição para as telas do famoso conto dos alemães Grimm, contém elementos explícitos e essenciais do flamenco e das touradas na nova história criada por Berger, por meio de referências a outras produções literárias, teatrais, musicais e fílmicas.

Os contos dos Grimm, assim como o filme de Berger, para além de outras relações intertextuais e intermidiáticas que podem ser estabelecidas, contêm muitos outros elementos que poderiam ser comparados. No entanto, a proposta deste artigo é dar início a um estudo, que será posteriormente ampliado e aprofundado, sobre o modo como foram transpostos midiaticamente elementos associados à cultura andaluza à luz dos estudos sobre intermidialidade em Blancanieves, em relação à (1) caracterização da personagem principal, Branca de Neve, (2) de seus pais, (3) do lugar e (4) da época em que ocorre a ação tanto do conto quanto do filme.

TradTerm, São Paulo, v.38, fevereiro/2021, p. 234-251

Número Especial - III JOTA

www.revistas.usp.br/tradterm 
Para isso, nos aproximaremos da teorização proposta por Irina Rajewsky (2012: 16) para quem o termo intermidialidade é cada vez mais utilizado e definido de distintas maneiras por diferentes abordagens de estudo, constituindo um termo genérico para tratar de fenômenos que acontecem entre mídias. A pesquisadora esclarece que, em sua concepção, embasada nos Estudos Literários, mas não limitada a eles, a intermidialidade é uma categoria para a análise concreta de textos ou de outros tipos de produtos das mídias (2012: 23) da qual devem ser distintos grupos de fenômenos que evidenciem qualidades intermidiáticas diferentes. Por esse motivo, Rajewsky propõe três subcategorias individuais de intermidialidade: transposição midiática, combinação de mídias e referências intermidiáticas. Claus Clüver (2011: 20), ao tratar do estudo da autora, enfatiza que essas subcategorias não são fixas e impermeáveis, ao contrário, e chama a atenção para textos nos quais são encontrados elementos de mais de uma dessas subcategorias. A autora também alerta para essa característica exemplificando-a em adaptações cinematográficas que

podem ser classificadas na categoria de combinação de mídias; como adaptações de obras literárias, elas podem ser classificadas na categoria de transposição midiática; e, se fizerem referências específicas e concretas a um texto literário anterior, essas estratégias podem ser classificadas como referências intermidiáticas (RAJEWSKY 2012: 26).

Vejamos um pouco mais de perto as ideias de Rajewsky (2012: 15) aproximando-as a uma reflexão sobre o filme de Berger. A combinação de mídias é aquela que abrange fenômenos como a ópera, o filme, quadrinhos, entre outras. A qualidade intermidiática dessa categoria é marcada pelo processo de combinar ao menos duas mídias convencionalmente distintas. Clüver (2011: 15) afirma que este é um aspecto marcante de todas as chamadas mídias plurimidiáticas (tais como o cinema e a ópera), nas quais várias outras mídias estão presentes. No filme de Berger, a presença de músicas e danças flamencas permite-nos pensar nessa classificação da autora.

Já a subcategoria das referências intermidiáticas trata de textos nos quais uma "mídia tematiza, evoca ou imita elementos ou estruturas de outra TradTerm, São Paulo, v.38, fevereiro/2021, p. 234-251

Número Especial - III JOTA www.revistas.usp.br/tradterm 
mídia" (RAJEWSKY 2012: 26). No filme Blancanieves, a referência ao conto é explícita; mas, como dito anteriormente, há claras alusões a produções em outras mídias, tanto ao romance Carmen quanto a elementos musicais, de dança, gestuais e plásticos do flamenco como também da tauromaquia.

E, finalmente, a transposição midiática, aquela na qual um texto em uma mídia "original" serve de "fonte" para um novo produto (RAJEWSKY 2012: 24). Entendemos aqui que a autora adota o termo "original" no sentido de 'primeira referência', a que colaborará para a recriação de outra mídia. Assim, um conto, filme, pintura ou outra mídia é considerado como texto 'original' que servirá de fonte para um novo texto em outra mídia, o 'textoalvo'. Em Blancanieves não apenas o conto Branca de Neve funciona como texto 'original'; também os vários elementos provenientes de outras mídias, sejam filmes, ópera, romance, dança e canto flamencos são explorados intermidiaticamente e fazem com que a produção percorra novos caminhos. Por esse motivo, algumas considerações, ainda que sucintas, sobre o flamenco no imaginário espanhol e para além dele são necessárias.

Ao tratar do filme Carmen la de Triana, de Rey (1938), Oliver Jover (2007: 26) argumenta que tanto em relação à ambientação da história quanto, principalmente, em relação às qualidades da personagem principal, a cigana Carmen, se estabelece o estereótipo homogeneizador que qualifica como iguais as categorias 'cigano/andaluz/espanhol', impedindo que as diferenças naturais entre cada uma delas sejam percebidas. Em suas palavras: "el tópico creado es tal que se confunden los términos: Carmen, gitano, andaluz y español" (2007: 26), uma vez que a imagem de Andaluzia projetada pelo filme "es una imagen pintoresca, típica, tópica, romántica en la línea del estereotipo consagrado a partir de la Carmen de Mérimée y con la iconografía legada por los ilustres viajeros románticos que visitaron nuestra tierra en el s. XX" (JOVER 2007: 165).

Francisco Aix Gracia faz uma observação semelhante, enfatizando a costumeira associação do flamenco como o representante da cultura andaluza e espanhola. Considera esse procedimento uma forte tendência essencialista na qual

TradTerm, São Paulo, v.38, fevereiro/2021, p. 234-251

Número Especial - III JOTA

www.revistas.usp.br/tradterm 
se interpreta el flamenco como el "alma incontaminada" de un pueblo (andaluz, gitano, desposeído, español, jerezano, etc.), como un cuerpo sustancial de tradiciones a preservar inmutables. Sería algo dado, un fenómeno cultural originario de un tiempo mítico, que surgió desempeñando una función social que hoy mantiene (2002: 110, destaques do autor).

O estudioso discorda dessa visão porque pesquisas específicas não indicariam um alto ou mesmo médio nível de consumo de produções de flamenco entre a população andaluza (AIX GRACIA 2002: 112). Além disso, destaca que o que se entende por flamenco apresenta na verdade uma considerável diversidade de tradições e tendências, existindo nele um caráter divergente e não homogeneizador como muitas vezes alguns desejam encontrar. Aix Gracia (2002), assim como Jover, ainda que tratando especificamente do filme de Rey, destacam que o estereótipo sobre Andaluzia teria sido construído por estrangeiros que visitavam a Espanha, mas também corroborado pelos próprios espanhóis "que contribuyen así al afianzamiento de este tópico, del que los andaluces parecen sentirse orgullosos o, al menos, complacientes" (JOVER 2007: 29).

Outro pesquisador, Gerhard Steingresse (2002), ressalta que o desejo de tomar o flamenco como "marcador de identidade cultural" não ocorre, como se poderia imaginar em um primeiro momento, apenas por parte dos estrangeiros. 0 autor encontra mais que uma complacência dos habitantes da região ou do país, e percebe ainda dentro desse procedimento um movimento mais organizado:

estamos, pues, ante el fenómeno de una ideologización de la cultura en función del restablecimiento de las bases de la cohesión social a través de la conciencia colectiva en una sociedad desideologizada y secularizada o, dicho de otro modo, ante un concepto neo-durkheimiano (STEINGRESSE 2002: 46).

Para o autor (2002: 48), apesar de o flamenco ser um elemento altamente compatível com os outros da cultura andaluza, não se produz necessariamente uma integração sociocultural generalizada para ele ser

TradTerm, São Paulo, v.38, fevereiro/2021, p. 234-251

Número Especial - III JOTA

www.revistas.usp.br/tradterm 
tomado como um "marcador de identidade", uma vez que não necessariamente todo andaluz e/ou todo sevilhano se identifica com a cultura flamenca e se sente, digamos, por ela representado. Além disso, Steingresse recorda também haver dentro do que comumente se costuma entender por "cultura flamenca" diferenças como aproximações mais ou menos fortes a elementos de uma chamada "cultura cigana". Portanto, conclui de modo bastante esclarecedor que:

no existe una cultura andaluza homogénea, "holística", en el sentido de "hecho social total", sino un conjunto de manifestaciones que participan en la generación de determinados estilos de vida, y sólo uno(s) está(n) relacionado(s) con el flamenco (STEINGRESSE 2002: 52, destaques do autor).

Não é minha intenção aqui colaborar com uma visão que busque homogeneizar e estereotipar o flamenco de modo a considerá-lo como igual à cultura cigana e/ou entender que ele representa a cultura sevilhana/andaluza e consequentemente uma cultura espanhola. Tampouco quero, ao menos neste momento, estender-me nessa problematização ao analisar o filme de Berger. Parece-me, que o diretor basco procura jogar intermidiaticamente com essas questões e com muitas obras que também as exploram.

Berger, logo no início de seu filme, evidencia ao espectador que a ação está ambientada em Sevilha, como veremos a seguir. Além disso, há vários elementos do flamenco e da tauromaquia muito associados entre si e, principalmente, no caso do primeiro, relacionado a elementos de uma cultura entendida como cigana e, estendidas muitas vezes, a uma imagem típica da Espanha ou ao menos do sul do país, Andaluzia. Não estou com isso deixando de reconhecer as muitas outras representações e culturas existentes em Sevilha, na Andaluzia e Espanha e de entender toda a conflituosidade que pode haver em cada uma delas; mas como essa associação é criada no filme, considerarei Blancanieves como uma versão sevilhana ou andaluza do conto dos Grimm, por estar ambientada nessa cidade e consequentemente nessa região; e abordarei como elementos em geral relacionados ao flamenco e à 
tauromaquia são trabalhados intermidiaticamente ao longo da produção de Berger.

\section{Blancanieves sevilhana}

A referência à obra dos alemães Grimm aparece explicitamente já nos primeiros minutos do filme. Ao se abrir uma cortina vermelha para os créditos, lê-se "Blancanieves / inspirada en un cuento de los hermanos Grimm" (0:01:03). Entretanto, após a apresentação dos créditos e diferentemente do que se esperaria encontrar, não temos imagens que lembrariam o início do famoso conto de fadas ${ }^{1}$. São apresentadas cenas em branco e preto com fotos antigas de uma cidade, onde se veem um rio, torres, casarios caiados, uma rua onde as casas têm grandes janelas com vasos, grades adornadas e faróis antigos. Essas são imagens que recordam o sul da Espanha, dentre as quais podem ser reconhecidos famosos pontos turísticos da cidade de Sevilha: La Giralda e a Torre del Oro². Por essas referências e pelas que virão nas próximas cenas, é possível concluir que o rio em questão é o Guadalquivir, que cruza essa cidade, e margeia o bairro Triana, famoso pela presença da cultura cigana flamenca e taurina ${ }^{3}$.

Temos então, segundo a subcategoria das referências intermidiáticas proposta por Rajewsky (2012: 26), claras referências a imagens encontradas em outras mídias, tais como produções fílmicas e em fotografias do início do século XX, que caracterizam a cidade andaluza e em especial o bairro Triana, tematizadas e evocadas para constituir a ambientação da produção do diretor basco.

No filme de Berger, logo a seguir, a câmera mostra a imagem de um cartaz antigo anunciando uma tourada e no qual se lê "6 hermosos toros de la afamada ganadería de Jesús Olivares / único matador Antonio Villalta"

\footnotetext{
1 Tomei duas versões do conto Branca de Neves para a língua portuguesa do Brasil, a de Belinky (2013) e a de Röhrig (2014). Em ambas temos ao início referências ao inverno, neve, reis, elementos não presentes no filme Blancanieves.

2 Imagens bastante semelhantes às do filme podem ser vistas no site "Vistas de Sevilla Antigua", https://www.youtube.com/watch?v=JSSjrNGGtsw. Acesso em: 18.01.2021.

${ }^{3}$ Há vários pequenos filmes com registros de imagens antigas e atuais que tratam de histórias desse bairro, como http://elpasadodesevilla.blogspot.com/. Acesso em: 18.01.2021.
}

TradTerm, São Paulo, v.38, fevereiro/2021, p. 234-251

Número Especial - III JOTA

www.revistas.usp.br/tradterm 
(0:02:56). Depois, vemos um bilhete de entradas com a data do evento, 21 de abril de 1910; a indicação da cidade, Sevilha; e mais explicitamente do local onde ocorrerá a tourada, Plaza de Toros La Colosal.

Após isso, temos imagens de pessoas caminhando e, na cena seguinte, em uma tomada mais ampla, pedestres e carros antigos em direção a um edifício arredondado (0:03:01) com fachada em forma de um portal em referência à Plaza de Toros de la Real Maestranza de la Caballería de Sevilla, conhecida como Catedral del Toreo. Entretanto, o nome da arena, Colosal, recorda o de outra que ficou na história da cidade apesar de sua curta vida, a Monumental. Outra alusão a essa arena aparece mais ao final do filme. Um jornal da época anuncia com uma foto de Blancanieves vestida como toureira com a manchete: "Triunfadora / el próximo 21 de abril tendrá su presentación en la Plaza de Toros La Colosal de Sevilla" (01:14:34). Depois disso, a câmera mostra a vista panorâmica da arena, sua fachada e um volante, no qual se vê a data, 21 de abril de 1929, dia e mês idênticos aos da última apresentação de Villalta e do nascimento da protagonista. A referência ao mês de abril é importante para caracterização de Sevilha. Nessa cidade, geralmente entre uma ou duas semanas depois da Semana Santa acontece uma grande festa regional chamada Fiestas de Primavera. Delas fazem parte a Feria de Abril ou Feria de Sevilla, as corridas de touro são praticamente o principal evento e, durante esses dias, muitos participantes usam os conhecidos trajes típicos sevilhanos.

Portanto, fica explícita, desde o começo do filme de Berger, a referência a Sevilha e a elementos relativos à tauromaquia e ao flamenco, preponderantemente relacionados a essa cidade.

\section{O nascimento de Carmen/Blancanieves}

Nesta sessão evidenciarei como elementos do conto recolhido pelos Grimm, conhecido até mesmo por quem não o leu, tal o modo como estão enraizados em nossa cultura de transmissão oral e em nosso imaginário, foram ressignificados a partir da introdução de elementos comumente caracterizados como pertencentes à cultura sevilhana, em especial ao TradTerm, São Paulo, v.38, fevereiro/2021, p. 234-251

Número Especial - III JOTA

www.revistas.usp.br/tradterm 
flamenco e às touradas, desde o momento do nascimento da protagonista do filme.

No conto, a rainha, mãe de Branca de Neve, ao furar o dedo enquanto costura olhando a neve pela janela, deseja ter uma filha branca como a neve, de faces coradas e lábios vermelhos como o sangue e cabelos negros como ébano da janela ${ }^{4}$. 0 desejo da mãe se concretiza e essas mesmas características despertarão inveja.

O filme de Berger não faz referência a essa parte do enredo do conto que trata do nome e caracterização da protagonista, mas mostra os momentos que antecedem o traumático nascimento de Carmen/Blacanieves, em que vemos o cotidiano do pai dela, não presente no conto. Na cena, o toureiro Antonio Villalta é vestido com seu traje de luces e reza diante de uma santa, provavelmente uma Nuestra Señora de los Dolores (0:03:57), beija uma medalha de ouro e a deixa nas mãos da imagem da santa. Todas essas referências, desde a preparação do toureiro, a indumentária, até a atitude religiosa, são alguns dos elementos muito associados à cultura das touradas. Os pais de Carmen/Blancanieves não são rei e rainha, como os do conto, mas são pessoas de prestígio e destaque no contexto social no qual estão inseridos.

$\mathrm{Na}$ medalha ofertada à santa de devoção vê-se a fotografia de uma mulher que se funde em close com sua imagem na plateia da arena de touros esperando para assistir ao espetáculo. Ao se abrir mais o foco da cena, vemos essa jovem e outra mais velha vestidas com a indumentária completa da típica mulher sevilhana das Ferias de Abril e também usada pelas bailaoras de flamenco: leque, vestido com estampado típico e seus adornos, mantilla e peineta (0:04:29). Ao começar a tourada, os intertítulos indicam que 0 espetáculo ocorrerá com seis touros e um único matador: Antonio Villalta. Apreensiva, a jovem mulher, além dos trajes típicos, leva no colo uma medalha semelhante à que o toureiro deixou nas mãos da santa. As imagens do toureiro vencendo os touros passam rapidamente pela tela. Até que chegamos ao sexto touro e de nome mais temível, Lúcifer (0:07:31).

\footnotetext{
${ }^{4} \mathrm{Na}$ tradução de Belinky (2013: 17), temos: "Enquanto costurava e olhava pela janela, ela furou o dedo com a agulha, e três gotas de sangue caíram sobre o tecido branco". E na de Röhrig (2014: 634): "Enquanto estava costurando e levantou o rosto para ver a neve, ela espetou o dedo com a agulha e três gotas de sangue caíram na neve".
}

TradTerm, São Paulo, v.38, fevereiro/2021, p. 234-251

Número Especial - III JOTA

www.revistas.usp.br/tradterm 
Antes da disputa final, o toureiro tira sua montera, dirige-se à jovem com roupas de bailaora que está na plateia $(0: 08: 07)$ e diz “¡Por ti y por el hijo que esperamos!", ofertando-lhe a montera, mas, para desapontamento da jovem e como um sinal de mau agouro, a peça cai no chão (0:08:29). É preciso lembrar a associação comumente feita entre o flamenco e a cultura cigana, por sua vez amplamente relacionada ao universo das superstições (Correa Navarrete 2016).

Interessante perceber que o elemento de mau agouro já presente no conto também pode ser percebido no filme de Berger. A religiosidade que há na devoção à santa está relacionada ao mundo do sincretismo da cultura cigana/sevilhana.

Começa a ocorrer a fatalidade, o touro investe contra Villalta, que fica gravemente ferido e, com isso, a mulher sente-se mal. Ambos estão no mesmo hospital que posteriormente será identificado como Nuestra Señora del Dolor de Sevilla e passam por cirurgias. Enfatizam-se as cenas de corte e de sangue. Apesar de o filme ser em branco e preto, o contraste entre a brancura das imagens do hospital, das roupas dos enfermeiros e as do casal atendido (0:11:09), e o escuro do sangue lembra o contraste do sangue na neve ou no tecido bordado pela mãe de Branca de Neve no conto. Além disso, o modo como as enfermeiras limpam e passam medicamentos na pele de Villalta, pelo tratamento das imagens cinematográficas, recordam a textura de um tecido (0:11:19). Nessas cenas também ganham destaque closes de objetos cortantes da cirurgia: pinças, tesoura, agulha e linha $(0: 11: 21)$ o que nos remete diretamente ao conto.

Neste momento temos uma quebra de expectativa, pois, diferentemente do que se poderia esperar pelo que vinha ocorrendo na ação do filme, mas se aproximando do conto, quem acaba morrendo é Carmen, Villalta perde os movimentos da perna e braços. Depois que a criança nasce (0:12:18), a mulher desfalece e então se vê a medalha caída no chão ao lado de um gotejar de sangue e nela a imagem de Villalta (0:12:35). Lemos nos intertítulos que "iCarmen de Triana, la mujer de Antonio Villalta, ha muerto!" (0:12:47). Com isso, sabemos não apenas o nome da mulher do toureiro, mas seu sobrenome ou nome artístico, que faz referência ao famoso TradTerm, São Paulo, v.38, fevereiro/2021, p. 234-251

Número Especial - III JOTA www.revistas.usp.br/tradterm 
bairro sevilhano. Imagens posteriores mostrarão um disco de Carmen de Triana sendo colocado em um gramofone e uma música tipicamente flamenca como se fosse cantada por ela mesma. Jover (2007: 18-19) argumenta que o nome Carmen passou a ser mais usado e associado à Espanha a partir do romance de Mérimée e depois disso transpôs fronteiras. Deste modo, percebese que no filme há um desejo de associar a personagem por seu nome, roupas e profissão ao bairro Triana e, mais do que isso, reforçar a associação desse local e seus habitantes à cultura do baile e música flamencos.

Temos outra referência à história de Branca de Neves quando a criança recém-nascida é levada ao pai ainda no hospital, a avó a retira do que deveria ser um pequeno berço, mas que mais se parece um caixão de vidro (0:15:30), mas o pai a rejeita.

Cenas depois, indicando a passagem do tempo por meio de fade-out, a câmera mostra um típico patio sevillano e ouvimos uma música flamenca (0:17:42). A avó costura um vestido branco, em cima de um banco brincando de dançar flamenco com todo seu gestual, vemos uma menina. A mulher a chama de 'Carmencita' e ficamos sabendo que o filho de Villalta e Carmen de Triana é uma menina $(0: 18: 07)$. Em vez de seguir os passos do pai, renomado toureiro, como provavelmente ele o desejaria (até mesmo por referir-se a filho, no masculino), vemos a filha seguindo os passos da mãe. Apesar de toda a alegria, como o estereótipo espera de uma sevilhana e de sua casa ${ }^{5}$, novamente algo corriqueiro, mas que denotará um mau agouro, acontece. Enquanto costura a roupa da neta, a avó fura o dedo. Vemos uma gota de sangue brotar e, como sabemos que estamos assistindo a uma obra inspirada em Branca de Neve, conhecemos a importância que esse incidente acaba por representar na história.

Após a primeira comunhão da menina, aparecem as cenas de uma comemoração na casa da avó (0:23:32); temos imagens dessa mulher dançando com sua neta. A câmera acompanha freneticamente os movimentos circulares da dança e o ritmo da música flamenca, quando abruptamente a mulher cai no chão e morre $(0: 25: 14)$, ao mesmo tempo em que se vê a agulha

\footnotetext{
${ }^{5}$ Jover detém-se sobre o estereótipo do que seria uma típica casa sevilhana em relação ao filme de Rey (1938) (2007: 22).

TradTerm, São Paulo, v.38, fevereiro/2021, p. 234-251

Número Especial - III JOTA

www.revistas.usp.br/tradterm
} 
do gramofone (presenteado à menina pelo pai) e a música pararem. Então, além da referência à agulha de costura em uma cena que lembra bastante a do conto ainda que protagonizada pela avó de Carmen/Blancanieves, temos a referência a outro objeto pontiagudo, a agulha do gramofone sinalizando a morte da mulher. É preciso recordar que a avó assumira a tarefa de criar a menina após a morte da mãe, sendo a encarregada de lhe passar a herança do conhecimento da cultura flamenca. A partir desse momento, Carmen ficará sob os cuidados, mais do que do pai, da madrasta, má e invejosa, como no conto dos Grimm.

Como fica bastante evidente a genealogia e formação de Carmen/Blacanieves são ressignificadas. Há uma origem, digamos, nobre dentro da comunidade a qual a família pertence, assim como está presente a referência ao mau agouro. Tudo indica até esse momento do filme que a menina, criada pela avó, seguirá os passos da mãe, famosa bailaora de flamenco.

\section{4. "Nunca dejes de mirar al toro": o aprendizado de Carmen/Blancanieves}

No conto Branca de Neve dos irmãos Grimm, podemos dizer que pouco sabemos dos pais da protagonista, além de ele ser um rei. Já no filme de Berger, Carmen/Blacanieves, após a morte da mãe, fica durante um período da infância afastada do pai e da madrasta, e aos cuidados da avó.

Entretanto, após a morte da avó é levada à casa paterna. O famoso toureiro já não está em seus dias de glória. Está entrevado em uma cadeira de rodas, mas é sob essa condição que a menina terá mais contato com o pai e receberá os ensinamentos da arte de tourear.

$\mathrm{Na}$ casa do pai, Carmencita desobedece à madrasta e sobe ao primeiro andar onde o pai está confinado. Além da cabeça de touro empalhada pendurada na parede remetendo ao vitorioso passado de Villalta, há no quarto um gramofone semelhante ao que ele enviou à filha no dia de sua primeira comunhão. Por meio desses elementos, acontecerá uma aproximação entre

TradTerm, São Paulo, v.38, fevereiro/2021, p. 234-251

Número Especial - III JOTA

www.revistas.usp.br/tradterm 
eles. Em outra cena (0:40:32), em uma alusão à passagem do tempo, em close, a menina vê um praxinoscópio girando com imagens de um toureiro. Em seguida (0:40:44), o pai, mesmo sem conseguir movimentar-se, ensina a menina a tourear com um touro empalhado e the dá um sábio conselho recordado por ela posteriormente: "Nunca dejes de mirar al toro" (0:42:08).

Carmencita demonstra que não aprendeu apenas os ensinamentos do pai, revela-se herdeira da cultura flamenca da mãe e o surpreende ao colocar o disco de Carmen de Triana, aparecer vestida de sevilhana e dançar para ele (0:42:47). Depois aos rodopios girando a cadeira de rodas do pai, dança com ele. E o ex-toureiro mais uma vez se lembra da mãe da menina.

Interessante perceber que, de modo distinto ao conto, a relação intermidiática estabelecida no filme proporciona um reencontro entre pai e filha. Apesar do abandono inicial, anos depois ocorre a reconciliação e o ensinamento: Villalta transmite à herdeira seus conhecimentos sobre o modo de desafiar o touro. Mas Carmencita também detém os conhecimentos provenientes de sua mãe e passados pela avó materna. 0 tempo passa e ela se torna uma moça, o pai morre e, após sofrer uma tentativa de assassinato pela madrasta, a moça traumatizada se esquecerá de suas origens e até mesmo de seu nome.

Se por um lado o empoderamento feminino herdado da mãe e da avó, bailaoras de flamenco estão presentes inicialmente na infância de Carmen/Blancanieves, na adaptação fílmica elementos da tourada são ressignificados na caraterização da protagonista. Podemos dizer que Carmen/Blancanieves está duplamente empoderada ao também levar adiante a arte de tourear aprendida com o pai. E será essa arte que a levará a uma nova vida, ao encontrar os integrantes de um circo e apresentar-se como toureira.

TradTerm, São Paulo, v.38, fevereiro/2021, p. 234-251

Número Especial - III JOTA

www.revistas.usp.br/tradterm 


\section{A herança de Carmen/Blancanieves: "Tengo que terminar la faena de mi padre"}

Em outra ressignificação da obra dos Grimm, Carmen agora se aproxima mais uma vez da história da Branca de Neve. Salva por uma trupe de anões que ganham a vida, entre outros números circenses, imitando touradas, Carmen é rebatizada; diz um dos anões: "Te llamaremos Blancanieves, como la del cuento" (01:03:35). Ela passa a tourear, viaja com a companhia dos anões, veste-se de toureira e faz sucesso por toda a Espanha (01:04:18).

Após a cena de sua apresentação no Colosal de Sevilha já mencionada, Carmen se ajoelha para rezar no mesmo gesto de seu pai anos antes e encontra a medalha que ele deixou nas mãos da estátua da santa. A câmera mostra imagens de um disco rodando em um gramofone, com a referência à Carmen de Triana. O ex-empresário do pai a reconhece e diz: “Hoy, Antonio de Villalta estaría orgulloso de su hija" (01:18:03) e os intertítulos mostram que o nome do toureiro soa familiar a ela. A partir desse momento, a moça começará a recobrar a memória, várias imagens passam rapidamente pela tela: o praxinoscópio, o grande quadro do pai vestido de toureiro, a janela do quarto onde ele era confinado, o touro empalhado com o qual ele a ensinou a tourear, o gramofone (01:20:17). Entrando na arena, ela vai recordando suas origens. Finalmente, dirá que deve continuar a "faena" de seu pai, Antonio Villalta, mostrando ter consciência de quem ela é filha.

Os intertítulos indicam: "Es la apoteosis, pero todo lo que empieza tiene que acabar" (00:21:53). Ela bravamente enfrenta o touro, recebe a montera de seu pai (01:27:33) e parece estar consagrada. Mas, assim como no conto, temos que recordar da invejosa madrasta e suas artimanhas, Carmen/Blancanieves come a maçã envenenada que aquela the prepara e cai morta (01:29:41).

Até este momento, nesta ressignificação intermidiática proporcionada pelo filme de Berger, o destino de Carmen/Blancanieves parece ser glorioso. Ela teria sucesso não ao levar adiante a arte de sua mãe, mas ao ganhar destaque como seguidora da arte do pai. Como toureira de sucesso, a

TradTerm, São Paulo, v.38, fevereiro/2021, p. 234-251

Número Especial - III JOTA

www.revistas.usp.br/tradterm 
protagonista estaria empoderada por meio de uma consagração em uma atividade mais associada ao mundo masculino, dominando touros perigosos, domando a força bruta, mas a história recontada pelo cineasta espanhol retoma drasticamente o conto dos Grimm.

\section{Conclusão: maldição ou milagre?}

A Carmen andaluza, que não é filha de reis, mas do toureiro Antonio Villalta e da bailaora e Carmen de Triana, pessoas muito provavelmente conhecidas e consagradas no ambiente sevilhano, segue tortuosamente seu destino de renascer Branca de Neve, ao ser batizada pela trupe de anões quando não tem lembrança de quem é.

Então temos uma inovação na história de Berger em relação ao conto Branca de Neve e às histórias das personagens Carmen. Não há um príncipe que a salve. A moça é herdeira da bravura de seu pai e da alegria de sua mãe, pôde defender-se e tourear. Mas essas características não a salvam de ser explorada como atração de circo. Todas as noites ela é beijada por quem pague o ingresso para tentar acordá-la. Um cartaz anuncia a "Feria de lo increíble / atracción única / El despertar de Blancanieves / ¿Quién será su príncipe?” (01:32:59) e, posteriormente, temos o intertítulo: “¿Milagro o maldición?" (01:33:47).

O final trágico que a produção intermidiática de Berger mostra ao expectador provoca uma reflexão sobre o lugar da protagonista que, ao contrário da do conto Branca de Neve, consegue destaque em uma carreira comumente considerada masculina e tem um final bastante distinto ao 'final feliz' do conto de fadas. Pode-se dizer que Carmen/Blancanieves constrói seu caminho para além daqueles herdados por seus pais, mas ironicamente, a personagem é ressignificada em relação ao desfecho do conto dos Grimm ao ser novamente exibida como uma atração de circo, aprisionada na reapresentação cíclica do beijo do príncipe que salva Branca de Neve.

Na obra de Berger não há um príncipe salvador, são os expectadores do circo que, repetidamente, imitarão a cena do beijo. Esse público, ao invés de ajudar a protagonista a se livrar de sua sina, fará com que ela seja TradTerm, São Paulo, v.38, fevereiro/2021, p. 234-251

Número Especial - III JOTA

www.revistas.usp.br/tradterm 
continuamente revivida. Impossível, não relacionar essa repetição à própria reprodução cinematográfica proporcionada pela exibição de um filme e o público do circo aos expectadores do cinema.

Berger, em Blancanieves, ressignifica o lugar e a época nos quais ocorre a ação de seu filme em relação ao conto dos Grimm, mas também personagens tais como os pais da personagem principal promovendo uma releitura intermidiática com elementos comumente associados à cultura cigana - o flamenco e a tauromaquia, por sua vez relacionados a região sul da Espanha - Andaluzia - e mais especificamente à cidade de Sevilha.

Entretanto, sem sombra de dúvida, é no personagem principal, Branca de Neve, que se percebe, de modo mais contundente, a ressignificação proposta pelo filme. A Blancanieves de Berger também volta à vida como a do conto dos Grimm, mas ao contrário do consagrado renascimento milagroso e feliz, a moça estará fadada a uma espécie de maldição ao se tornar atração de circo com seus antigos colegas anões. Carmen/Blancanieves mesmo dominando as artes do flamenco e além dessas, as das touradas, não consegue se livrar de um destino trágico como a das outras Carmen. 


\section{Referências}

AIX Gracia, F. El arte flamenco como campo de producción cultural. Aproximaciones a sus aspectos sociales. Anduli - Revista Andaluza de Ciencias Sociales. n. 1, 2002, p. 109-125.

BlanCANIEVES. Direção: Pablo Berger. Produção: Ibon Cornenzana, Jérôme Vidal e Pablo Berger. Intérpretes: Maribel Verdú, Daniel Gimenéz Cacho, Pere Ponce, José María Pou, Inma Cuesta, Ángela Molina, Sofía Oria, Macarena García. Roteiro: Pablo Berger. Arcadia Motion Picture, 2012, 1 DVD (aprox. 104 min.), mudo, P\&B. Distribuidor: Imovision, 2013.

ClÜVER, C. Intermidialidade. Aletria. Revista de Estudos de Literatura. Belo Horizonte: UFMG, v. 1, n. 2, p.3-23. nov. 2011.

Correa Navarrete, T. Religiosidad y moral en el mundo gitano, 2016. https://silo.tips/download/religiosidad-y-moral-en-el-mundo-gitano. Acesso em: 15.01.2021.

Jover Oliver, R. Andalucía desde Berlín: Carmen la de Triana. Frame: Revista de cine de la Biblioteca de la Facultad de Comunicación, n. 1, 2007, p. 162-177.

Grimm, J.; Grimm, W. Branca de Neve. Tradução Tatiana Belinky. São Paulo: Editora Melhoramentos, 2013.

Grimm, J.; Grimm, W. "Branca de Neve". In: GrimM, J.; GrimM, W. Contos maravilhosos, infantis e domésticos. Tradução Cristine Röhrig. São Paulo: Editora Cosac Naify, 2014, p. 634-740.

RAJEWSKY, I. Intermidialidade, Intertextualidade e “Remediação". Uma Perspectiva Literária sobre a Intermidialidade. Tradução Thaïs F.N. Diniz e Eliana L. L. Reis. In: DINIZ, Thaïs F. N (Org.). Intermidialidade e Estudos Interartes. Desafios da arte contemporânea. Belo Horizonte Editora da UFMG, 2012, p. 15-45.

STEINGRESSE, G. El flamenco como patrimonio cultural o una construcción artificial más de la identidad andaluza. Anduli - Revista Andaluza de Ciencias Sociales. n. 1, 2002, p. 43-64.

Recebido em: 27/02/2020

Aceito em: 22/09/2020

Publicado em fevereiro de 2021

TradTerm, São Paulo, v.38, fevereiro/2021, p. 234-251

Número Especial - III JOTA

www.revistas.usp.br/tradterm 